\title{
Article \\ A New Extremotolerant Ecotype of the Fungus Pseudotaeniolina globosa Isolated from Djoser Pyramid, Memphis Necropolis, Egypt
}

\author{
Samah Mohamed Rizk ${ }^{1,2,3, *(D)}$, Mahmoud Magdy ${ }^{2}\left(\mathbb{D}\right.$, Filomena De Leo $\left.^{3}{ }^{(}\right)$, Olaf Werner $^{1}{ }^{(D)}$, \\ Mohamed Abdel-Salam Rashed ${ }^{2}$, Rosa Maria Ros ${ }^{1}{ }^{1}$ and Clara Urzì ${ }^{3}$ \\ 1 Department of Plant Biology, Faculty of Biology, Murcia University, 30100 Murcia, Spain; \\ werner@um.es (O.W.); rmros@um.es (R.M.R.) \\ 2 Genetics Department, Faculty of Agriculture, Ain Shams University, Cairo 11241, Egypt; \\ m.elmosallamy@agr.asu.edu.eg (M.M.); rashed5012@agr.asu.edu.eg (M.A.-S.R.) \\ 3 Department of Chemical, Biological, Pharmaceutical and Environmental Sciences, University of Messina, \\ 98166 Messina, Italy; fdeleo@unime.it (F.D.L.); urzicl@unime.it (C.U.) \\ * Correspondence: samah.mohamed@um.es; Tel.: +20-1093411288
}

Citation: Rizk, S.M.; Magdy, M.;

De Leo, F.; Werner, O.;

Rashed, M.A.-S.; Ros, R.M.; Urzì, C. A New Extremotolerant Ecotype of the Fungus Pseudotaeniolina globosa Isolated from Djoser Pyramid, Memphis Necropolis, Egypt. J. Fungi 2021, 7, 104. https://doi.org/ 10.3390/jof7020104

Academic Editor: Macit Ilkit

Received: 10 January 2021

Accepted: 28 January 2021

Published: 2 February 2021

Publisher's Note: MDPI stays neutral with regard to jurisdictional claims in published maps and institutional affiliations.

Copyright: ( $\odot 2021$ by the authors Licensee MDPI, Basel, Switzerland. This article is an open access article distributed under the terms and conditions of the Creative Commons Attribution (CC BY) license (https:// creativecommons.org/licenses/by/ $4.0 /)$.

\begin{abstract}
Most of the rock-inhabiting fungi are meristematic and melanized microorganisms often associated with monument biodeterioration. In previous microbial profiling of the Egyptian Djoser pyramid, a Pseudotaeniolina globosa isolate was found. The current study aimed to characterize the P. globosa isolated from the Djoser pyramid compared with an Italian isolate at morphological, physiological, and molecular levels. Experiments were carried out to test temperature, salinity, and $\mathrm{pH}$ preferences, as well as stress tolerance to UV radiation and high temperature, in addition to a multilocus genotyping using ITS, nrSSU or 18S, nrLSU or 28S, BT2, and RPB2 markers. Morphological and molecular data confirmed the con-specificity of the two isolates. However, the Egyptian isolate showed a wider range of growth at different environmental conditions being much more tolerant to a wider range of temperature $\left(4-37^{\circ} \mathrm{C}\right)$ and $\mathrm{pH}$ values $(3.0-9.0 \mathrm{pH})$ than the Italian $\left(10-30{ }^{\circ} \mathrm{C}\right.$, $4.0-6.0 \mathrm{pH})$, and more tolerant to extreme salinity levels $(5 \mathrm{M} \mathrm{NaCl})$, compared to the lowest in the Italian isolate $(0.2 \mathrm{M} \mathrm{NaCl})$. Besides, the Egyptian isolate was more tolerant to high temperature than the Italian isolate since it was able to survive after exposure to up to $85^{\circ} \mathrm{C}$ for $5 \mathrm{~min}$, and was not affected for up to $9 \mathrm{~h}$ of UV exposure, while the Italian one could not regrow after the same treatments. The Pseudotaeniolina globosa species was attributed to the family Teratosphaeriaceae of the order Capnodiales, class Dothideomycetes. Our results demonstrated that the Egyptian isolate could be considered an ecotype well adapted to harsh and extreme environments. Its potential bio-deteriorating effect on such an important cultural heritage requires special attention to design and conservation plans and solutions to limit its presence and extension in the studied pyramid and surrounding archaeological sites.
\end{abstract}

Keywords: black yeasts; Capnodiales; Dothideomycetes; halotolerant fungi; multi-locus genotyping; rock-inhabiting fungi; Teratosphaeriaceae

\section{Introduction}

Black meristematic fungi or micro-colonial fungi [1,2], which were more recently referred to as "rock-inhabiting fungi" (RIF) [3], are slow-growing microorganisms often associated with natural rocky substrates $[4,5]$. To economize the energy requirements in extreme environments, their life cycles are simplified [6], lacking morphologically differentiated sexual phases, and producing only a few metabolites and morphological structures crucial for survival [7]. This group of fungi possesses peculiar characters related to stress tolerance (e.g., melanized cell walls), enabling them to successfully reside under harsh climatic conditions of prolonged desiccation, extreme temperatures (even in Arctic 
habitats), high solar irradiation and osmotic stress, and limited nutrient availability [6,8], where cosmopolitan and fast-growing micro-fungi are unable to survive [5]. Although the role of black meristematic fungi in monument decay remained underestimated for a long time, it is now clear that they are among the most active groups of microorganisms causing weathering of rocks and biodeterioration of monuments exposed to outdoor conditions [9-15] in addition to their consistent detection on marble monuments in the Mediterranean basin [16-20].

The taxonomic diversity of RIF appears to be unexpectedly wide, although only a limited number of RIF species and genera have been described [21]. Several studies have revealed that the ability of micro-fungi to grow on rocky substrates is a polyphyletic trait, assessing RIF in two different classes of Ascomycota, namely Dothideomycetes (mainly the orders Capnodiales, Dothideales, and Pleosporales) and Eurotiomycetes (order Chaetothyriales) $[3,22-26]$. Their identification also remained relatively intuitive because of their scarce differentiation and morphological plasticity, until molecular techniques became common in fungal systematics. With the improvement of isolation procedures and molecular methods, it has become apparent that RIFs are much more common and widespread than previously believed [3].

Within the RIF group, Pseudotaeniolina J.L. Crane \& Schokn. (order Capnodiales) was introduced as a monotypic genus for a species isolated from plant material named P. convolvuli (Esfand.) J.L. Crane \& Schokn. De Leo et al. [16] isolated the second species, P. globosa De Leo, Urzii \& De Hoog, from the outside wall of the church of "Santa Maria di Mili" in Messina, Italy. These authors described it as an anamorphic, melanized fungus with meristematic development followed by arthric secession leading preponderantly to single cell formation. The identification was supported by SSU (small subunit) and ITS (internal transcribed spacer) rDNA sequence data. However, the family name was still not assigned [27]. Currently, P. globosa has few isolates worldwide and a limited dataset available in the GenBank database (https:/ / www.ncbi.nlm.nih.gov/genbank/, accessed August, 2020).

Physical, chemical, and biological factors play a combined role in weathering archaeological sites suffering from biodeterioration. Previously, in Egyptian monuments, species from genera Alternaria Nees, Aspergillus P. Micheli ex Haller, Bipolaris Shoemaker, Cladosporium Link, Dichotomopilus X. Wei Wang, Samson \& Crous, Fusarium Link, Rhizopus Ehrenb. and Penicillium Link were reported from several archaeological remains. Among these are the archaeological tombs in Alexandria city [28], Tuna el-Gabel's excavations near Al-Minya city [29], the Great pyramid complex (Giza city), the Mosque of judge Abd El basset (Cairo city), the Museum of Ismailia Antiquities (Ismailia city), the National Museum of Egyptian Civilization (Cairo city), Senusret I obelisk (Fayoum city), and Seti I tomb (Abydos city) as described by Mohamed \& Ibrahim [30]. Besides, a microbial survey performed in the Djoser pyramid complex using metabarcoding and traditional isolation methods found Pseudotaeniolina globosa on Egyptian archaeological remains (unpublished), this being the second worldwide report of the species after its description in Messina by De Leo et al. [16].

This study aimed to deepen the previous finding and had the following specific objectives: (1) to evaluate if the sample of $P$. globosa isolated from the step pyramid of Djoser corresponds to the same isolate found previously in Messina or is perhaps an extremotolerant ecotype; (2) in an affirmative case, to describe this ecotype, characterizing it at morphological, physiological and molecular levels and knowing its UV and temperature tolerance; (3) to better clarify the taxonomic position within the order Capnodiales based on multi-locus genotyping identification.

\section{Materials and Methods}

\subsection{Isolate Sampling}

The Pyramid of Djoser, also known as the "Step Pyramid", is an archaeological remain in the Saqqara region in the Memphis necropolis, located in the northern part of the Nile 
Valley, situated at $29^{\circ} 52^{\prime} 10.17^{\prime \prime} \mathrm{N}$ and $31^{\circ} 13^{\prime} 8.70^{\prime \prime} \mathrm{E}$ in the Giza governorate, Egypt. The Pseudotaeniolina globosa isolate used in the current study, coded as DPS10, was obtained from soil particles collected at the Djoser pyramid's ground entrance using Dichloran Rose Bengal Chloramphenicol (DRBC) agar medium (\#CM0727, Oxoid, Ontario, Canada). The nomenclature of fungi follows Index Fungorum (http:/ / www.indexfungorum.org).

\subsection{Morphological Characterization of Pseudotaeniolina Globosa}

Hyphal maturation and conidiogenesis were observed. Culture media preference experiments were also performed.

\subsubsection{Hyphal Maturation and Conidiogenesis}

These were studied using light and phase contrast microscopy on slide cultures performed by inoculating the DPS10 in squared agar blocks of Malt Extract Agar (MEA; $\# 1038$, Condalab, Madrid, Spain). The slide cultures were incubated for one month at $25^{\circ} \mathrm{C}$ in wet sterile Petri dishes with filter paper to avoid media dehydrating and observed using lactophenol by a Leica DMLB Tilting Trinocular Phase Contrast $(100 \times)$ and Dark Field Light Microscope $(100 \times)$. Digital images were captured using a Leica DFC500 digital color camera optimized with the software Micromax Arkon (v. 8.12.05).

\subsubsection{Culture Media Preferences}

Characteristics and growth rates of the colonies were studied and recorded after one month, performed in duplicates of divided Petri dishes of four sections, which contained MEA, Potato Dextrose Agar (PDA; \#1022, Condalab, Spain), Oatmeal Agar (OMA; \#2060, Condalab, Spain), and Czapek Dox Agar (CzA; \#1015, Condalab, Spain) incubated at $25^{\circ} \mathrm{C}$.

\subsection{Physiological Characterization of Pseudotaeniolina Globosa}

Temperature preferences, growth at different salt concentrations, and growth at different $\mathrm{pH}$ were performed according to Selbmann et al. [8]. Colonies with diameter $>2 \mathrm{~mm}$ were considered positive, according to Kane \& Summerbell [31]. Comparisons with an Italian isolate (MC769) of the species were made based on the data reported by De Leo et al. [16].

\subsubsection{Temperature Preferences}

PDA Petri dishes divided into four sections in duplicates containing the DPS10 isolate were incubated at $4,10,25,30,34$, and $37^{\circ} \mathrm{C}$. The colony diameter was recorded after one month of incubation to detect the isolate's optimum growth among the different selected temperatures.

\subsubsection{Growth at Different Salt Concentrations}

An experiment was performed to test the ability of the fungus to grow in the presence of a different concentration of salts and to recognize its salinity preference by inoculating the DPS10 isolate on four spots in duplicates of MEA plates supplemented with a scale of $\mathrm{NaCl}$ concentrations of $1.2,1.5,3.0,5.0,7.0,10.0,12.0,15.0,18.0,25.0$, and $30.0 \%$, incubated at $25^{\circ} \mathrm{C}$ for one month.

\subsubsection{Growth at Different $\mathrm{pH}$}

The DPS10 isolate capacity to grow at different $\mathrm{pH}$ values was tested in triplicates of MEB medium at $\mathrm{pH}$ levels of 1.0, 2.0, 3.0, 4.0, 5.0, 6.0, 7.0, 8.0, and 9.0. At standard conditions for RIFs $\mathrm{pH}$ growth [8], the experiment was initially performed at $\mathrm{pH} 5.0$ by $1 \mathrm{~N} \mathrm{HCl}$; then media was adjusted for $\mathrm{pH} 1.0$ using $\mathrm{HCl} / \mathrm{KCl}$ buffer and for $\mathrm{pH} 2.0-7.0$ by using Mcllvaine solution and for $\mathrm{pH}$ 8.0-9.0 by applying Clark \& Lubs solution. DPS10 isolate was incubated at $25^{\circ} \mathrm{C}$ for one month in a shaken culture at $70 \mathrm{rpm}$ [32]. 


\subsection{Tolerance Assessment of Pseudotaeniolina Globosa}

As P. globosa is exposed to the sun and dryness prevailing in the Djoser pyramid area, it is supposed to be adapted to this arid environment. In addition to the DPS10, isolate MC769 of P. globosa (CBS 109889T) [16] was used for tolerance assessment and molecular analyses. The MC769 was obtained from the fungal collection of the Department of Chemical, Biological, Pharmaceutical and Environmental Sciences, University of Messina, Italy, and freshly re-cultivated using the culture medium Malt Extract Broth (MEB; \#CM0057, Oxoid, USA). Experiments were designed to recognize the extreme UV radiation levels and temperature that the DPS10 and MC769 isolates can tolerate.

\subsubsection{UV Tolerance under Wet and Dry Conditions}

The ability of the fungus to survive and reproduce after exposure to germicide UV$C$ radiation $(253.7 \mathrm{~nm})$ in wet and dry conditions was tested. The experiment material was prepared in replicates by placing about $1 \mathrm{~cm}^{2}$ mycelia of one month old cultures of DPS10 and MC769 isolates in an open sterile Petri dish each along with $1 \mathrm{~mL}$ physiological solution $(0.9 \% \mathrm{NaCl})$, where the solution was not more than $1 \mathrm{~mm}$ deep (wet condition), or without the physiological solution (dry condition). The Petri dishes were then placed at $35 \mathrm{~cm}$ from the UV lamp (Philips TUV T8 30W). The sampling was done in duplicates after 10 and $30 \mathrm{~min}, 1,3,6,9,12$, and $24 \mathrm{~h}$. The treated mycelia under wet and dry conditions were re-planted in PDA medium and incubated at $25^{\circ} \mathrm{C}$ for one month to record their regrow ability.

\subsubsection{Heat Stress Tolerance}

The experimental aim was to identify the degree of the fungus ability to survive and resume growth after the exposure of the cells to high-temperature stress. The experiment was performed in duplicates by harvesting about $1 \mathrm{~cm}^{2}$ mycelia of one month old cultures of DPS10 and MC769 isolates and transfer them to $1 \mathrm{~mL}$ of physiological solution in $2 \mathrm{~mL}$ tubes. The tubes were put in a water bath adjusted to $65^{\circ} \mathrm{C}$ up to $85^{\circ} \mathrm{C}$ in $5^{\circ} \mathrm{C}$ intervals. The sampling was done in duplicates after 2, 5, 10, and $15 \mathrm{~min}$ of exposure at each temperature. The same was repeated in dry conditions using hot blocks without a physiological solution. The treated mycelia from both wet and dry conditions were re-planted in PDA medium and incubated at $25{ }^{\circ} \mathrm{C}$ for one month.

\subsection{Molecular Characterization of Pseudotaeniolina Globosa}

Molecular characterization of both isolates and family assignment of $P$. globosa were performed using a PCR based approach combined with Sanger sequencing, commonly known as "multi-locus genotyping" using five molecular markers.

\subsubsection{DNA Extraction}

DNA for both fungal isolates was extracted using cetyltrimethylammonium bromide (CTAB) acid-washed beads using the manual protocol of Möller et al. [33] and modified by Urzì et al. [34]. DNA was quantified with Qubit ${ }^{\mathrm{TM}}$ and the Qubit ${ }^{\mathrm{TM}}$ dsDNA BR assay kit (Invitrogen, Thermo Fisher Scientific, Massachusetts, MA, USA).

\subsubsection{Multi-Locus Genotyping}

The loci that were amplified for multi-locus comparison between the two isolates were the ITS, the small subunit of the nuclear ribosomal RNA (nrSSU or 18S), the large subunit of the nuclear ribosomal RNA (nrLSU or 28S), B-tubulin (BT2), and RNA polymerase II (RPB2) [21]. Primers are listed in Table 1.

PCR reactions were performed using the MyTaq ${ }^{\mathrm{TM}}$ Red Mix (Cat\# BIO-25043, BioLine, London, UK). Each $25 \mu \mathrm{L}$ reaction tube included 5 pmol of each primer, and $40 \mathrm{ng}$ of template DNA. The amplification was carried out using a Techne ${ }^{\mathrm{TM}} 512$ thermocycler (Techne, Staffordshire, UK). The PCR programs were adjusted according to the primer pair melting temperature (Tm) as follows: the first denaturation step at $95^{\circ} \mathrm{C}$ for $5 \mathrm{~min}$ 
was followed by 33 cycles of denaturation at $95^{\circ} \mathrm{C}$ for $30 \mathrm{~s}$, annealing at the assigned temperature (see Table 1) for $30 \mathrm{~s}$, extension at $72{ }^{\circ} \mathrm{C}$ for $30 \mathrm{~s}$ and a final extension $72{ }^{\circ} \mathrm{C}$ for 5 min.

PCR products were visualized using 1.5\% agarose gel electrophoresis in 1x TBE buffer. When successful, all PCR reactions were prepared for the cleanup step (purification) using GeneJET ${ }^{\mathrm{TM}}$ PCR purification kit (K0702, Fermentas, Thermo Fisher Scientific, Massachusetts, MA, USA) before automated Sanger sequencing (ABI 3730xl System, Macrogen, Inc., Seoul, Korea). Chromatographs of both directions were trimmed, assembled, and aligned using Geneious Prime [35] and blasted for species identification using the3 NCBI online Blast tool (https://blast.ncbi.nlm.nih.gov/Blast.cgi). Retrieved sequences were revised and checked using GenBank nucleotide database (https: //www.ncbi.nlm.nih.gov/nuccore).

Taxonomic ranking and phylogenetic relationships were retrieved from the NCBI taxonomy database (https: / / www.ncbi.nlm.nih.gov/taxonomy). Alignments of the target sequences and the BLAST query results were performed using ClustalW [36] using the default settings, while repeated sequences were discarded. Phylogenetic trees were constructed by the maximum likelihood method based on the Generalized Time-reversible (GTR) model using Fasttree v2.1.5 [37].

Table 1. Multi-locus primers used for the identification of Pseudotaeniolina globosa from literature.

\begin{tabular}{cccc}
\hline Locus & Primer (Direction) & Annealing $\left({ }^{\circ} \mathrm{C}\right)$ & Reference \\
\hline \multirow{2}{*}{ ITS } & ITS1 (F) & 50 & {$[38]$} \\
& ITS4 (R) & & \\
& NS1 (F) & & {$[38]$} \\
\multirow{2}{*}{ nrSSU } & NS3 (F) & 55 & \\
& NS5 (F) & & {$[39]$} \\
& NS7 (F) & 52 & {$[40]$} \\
& NS24 (R) & 52 & {$[41]$} \\
\hline \multirow{2}{*}{ nrLSU } & LSU1Fd (F) & 52 & {$[42]$} \\
\multirow{2}{*}{ BT2 } & LR5 (R) & \multirow{2}{*}{ T1 } & \\
\hline \multirow{2}{*}{ RPB2 } & T22 & & \\
\hline
\end{tabular}

\section{Results}

\subsection{Morphological Characterization of Pseudotaeniolina Globosa}

\subsubsection{Hyphal Maturation and Conidiogenesis}

The DPS10 isolate was anamorphic. Colonies grew slowly as they reached $21.0 \pm 0.8 \mathrm{~mm}$ in diameter after one month. Yeast-like cell forms were absent, and the teleomorph was not observed. Black colonies were butter-like (butyreae); they became shiny and of more rigid structure and wrinkled, with a cauliflower shape, with age. The mycelium was composed of pale brown, thick-walled immersed, branched hyphal cells, 7.0-12.0 $\mu \mathrm{m}$ long, and $4.0-6.0 \mu \mathrm{m}$ wide. The meristematic mycelium eventually converted into multicellular clumps, 5.0-12.0 $\mu \mathrm{m}$ in diameter. Conidia were produced by arthric disarticulation of hyphae; these were uni- or bi-cellular, pale brown, constricted at the septa, and 4.8-5.5 $\mu \mathrm{m}$ in diameter (Figure 1). 


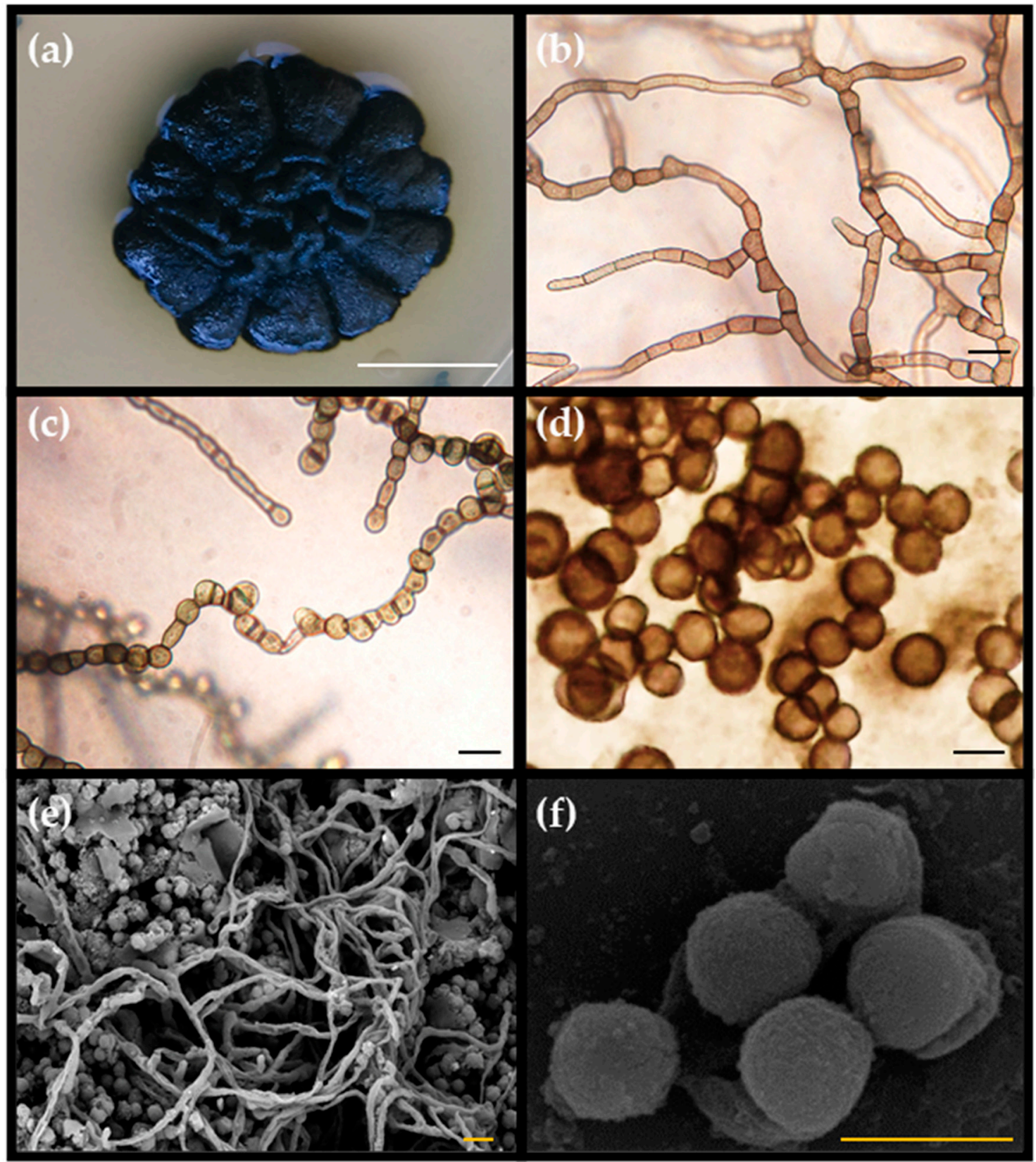

Figure 1. Pseudotaeniolina globosa DPS10 isolate morphology. (a) Colony after one-month incubation on Malt Extract Agar (MEA) medium; (b) Developing hyphae; (c) Clumps of meristematic structure; (d) Mature spherical conidia; (e) Hyphal structure and mature conidia; (f) Mature conidia. (a-d) Micrographs under the light microscope. (e,f) Micrographs under the Scanning Electron Microscope. White bar $=1 \mathrm{~cm}$, black bars $=20 \mu \mathrm{m}$, and orange bars $=10 \mu \mathrm{m}$.

\subsubsection{Culture Media Preferences}

The isolate DPS10 was able to grow and reproduce on different culture media after one month of incubation at $25^{\circ} \mathrm{C}$. On PDA, it showed a visible optimum growth with a diameter record of $21.0 \pm 0.8 \mathrm{~mm}$, with black, shiny, hard, wrinkled structure and a cauliflower shape, slightly raised at the center (umbonate), radially folded, with a unique appearance of an olive-green glow surrounding the colony edge. On MEA and CzA media, it showed a small reduction of $19.5 \pm 0.7 \mathrm{~mm}$ in diameter, while the same morphological appearance was observed, except an olive-green color on MEA, and change from umbonate to crateriform with leathery texture on CzA. The smallest ultimate colony diameters were observed on the OMA medium, being $18.5 \pm 0.8 \mathrm{~mm}$ in diameter, with a different appearance of a flat, 
hairy, gray growth on the colony top. No changes in the conidia morph among the tested media were observed (Figure 2).

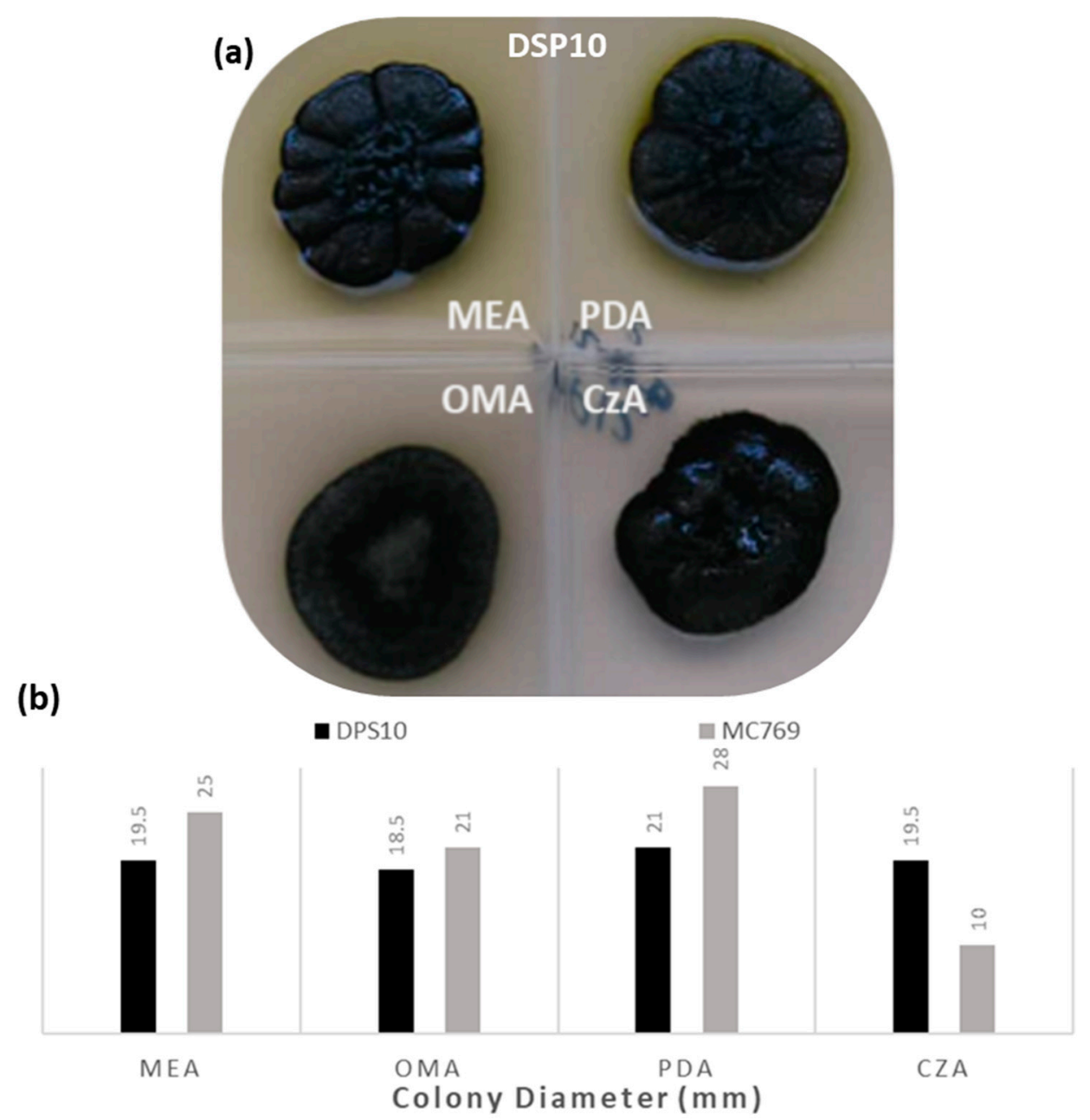

Figure 2. Colonies of Pseudotaeniolina globosa grown on different media (MEA, Oatmeal Agar (OMA), Potato Dextrose Agar (PDA), Czapek Dox Agar (CzA)). (a) Colonies of DPS10 isolate on the four media; (b) Colonies diameter are compared with MC769 isolate according to published data by De Leo et al. [16].

As reported by De Leo et al. [16], MC769 isolate colony on PDA showed the highest growth record of $28.0 \mathrm{~mm}$ in diameter with flat, regular margin, slightly raised at the center, cerebriform, and radially folded. On MEA, the colony was black and shiny, buttery, flat, slightly raised at the center and of $25.0 \mathrm{~mm}$ in diameter. It had a sharp, regular margin of $21.0 \mathrm{~mm}$ diameter on OMA, while the colony on CzA was flat, with a fimbriate margin, attaining up to $10.0 \mathrm{~mm}$ diameter (Figure 2).

\subsection{Physiological Characterization of Pseudotaeniolina Globosa}

\subsubsection{Temperature Preferences}

The DPS10 isolate grew and reproduced at a wide range of temperatures, ranging from 4 to $37^{\circ} \mathrm{C}$, with the optimum growth observed at $25^{\circ} \mathrm{C}$ where the colony reached $21.0 \pm 0.7 \mathrm{~mm}$ in diameter. Above this temperature, a considerable reduction of colony diameter occurred at $30^{\circ} \mathrm{C}$ with $13.7 \pm 0.3 \mathrm{~mm}$, and $37^{\circ} \mathrm{C}$ with $4.8 \pm 0.4 \mathrm{~mm}$ in diameter. At the lowest temperature at which the colony was able to grow, it reached $7.0 \pm 0.7 \mathrm{~mm}$ in diameter. Considering these data, it can be referred to as a mesophilic-psychrotolerant fungus. In comparison, as De Leo et al. [16] reported, the isolate MC769 showed the 
same diameter of optimum growth at $25^{\circ} \mathrm{C}$ and near same diameter, between 10 to $30^{\circ} \mathrm{C}$, without any record of growth at lower and higher temperature degrees (Figure 3 ).

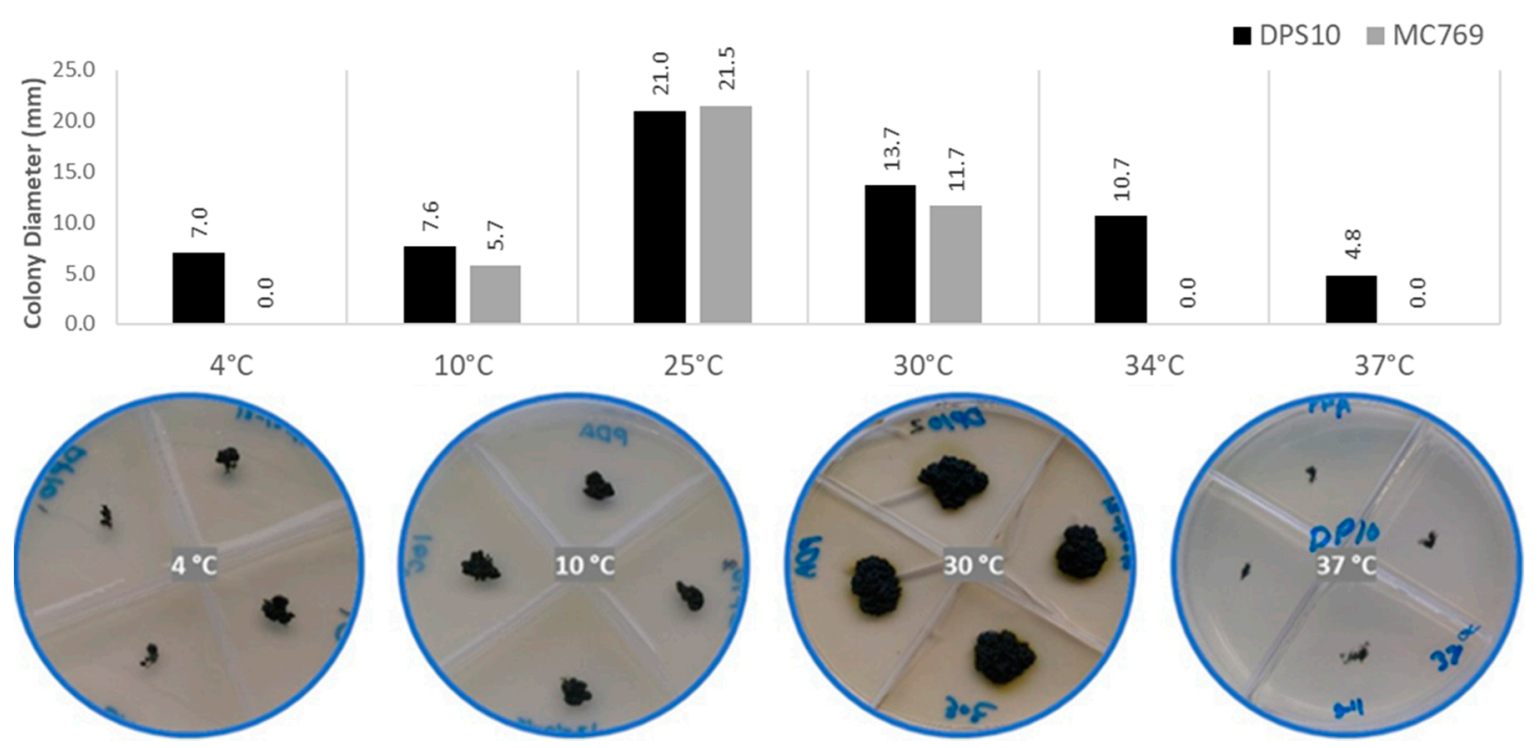

Figure 3. Temperature preferences of Pseudotaeniolina globosa DPS10 isolate shown by the colony diameter reached on PDA medium after one-month incubation. The column chart in the upper part exhibit comparison of DPS10 and MC769 isolates at $4,10,25,30,34$, and $37^{\circ} \mathrm{C}$. Visual examination of the colonies in the lower part shows the growth of DPS10 at 4, 10, 30, and $37^{\circ} \mathrm{C}$ in quadruplicates (Petri dish of four divisions). Data on MC769 isolate come from De Leo et al. [16].

\subsubsection{Growth at Different $\mathrm{NaCl}$ Concentrations}

The DPS10 isolate could grow at all the tested $\mathrm{NaCl}$ concentrations, even at $30.0 \%$, the maximum checked. It showed colonies of $22.0 \pm 0.5$ to $18.5 \pm 1.2 \mathrm{~mm}$ diameter up to $10.0 \%$ of $\mathrm{NaCl}$ concentration and showed a limited reduction of colony diameter of $17.0 \pm 1.9$ and $14.6 \pm 1.6 \mathrm{~mm}$ at $12.0 \%$ and $15.0 \% \mathrm{NaCl}$ concentration, respectively; and a considerable reduction to $9.5 \pm 1.7$ and $7.5 \pm 0.8 \mathrm{~mm}$ at $18.0 \%$ and $30.0 \% \mathrm{NaCl}$ concentration, respectively. Differently, MC769 isolate only grew at a maximum of $1.2 \% \mathrm{NaCl}$ concentration as reported by De Leo et al. [16] (Figure 4).

\subsubsection{Growth at Different $\mathrm{pH}$}

The DPS10 isolate showed an ability to grow at a wide range of $\mathrm{pH}$ values (from $\mathrm{pH} 3.0$ to $\mathrm{pH}$ 9.0). The maximal growth was recorded between $\mathrm{pH} 5.0$ and $\mathrm{pH} 7.0$, and the minimal growth was recorded at $\mathrm{pH} 3.0$ and $\mathrm{pH}$ 9.0. Based on the data from De Leo et al. [16], MC769 isolate showed growth at a narrower range of $\mathrm{pH}$ values (from $\mathrm{pH} 4.0$ to $\mathrm{pH} 7.0$ ), with maximal growth at $\mathrm{pH} 5.0$ and minimal growth at $\mathrm{pH}$ 7.0. Comparing the two isolates, both started to grow at $\mathrm{pH} 4.0$ with optimal growth up to $\mathrm{pH} 5.0$ for MC769 and up to $\mathrm{pH} 7.0$ for DPS10 and continued with growth reduction to $\mathrm{pH}$ 9.0. On the contrary, MC769 showed no growth at $\mathrm{pH} 8.0$ (Figure 5).

\subsection{Tolerance Experiments of Pseudotaeniolina Globosa \\ 3.3.1. UV Tolerance under Wet and Dry Conditions}

The isolates DPS10 and MC769 showed an equal maximum growth rate after UV exposure of $10 \mathrm{~min}$ until $6 \mathrm{~h}$; the isolates maintained the same colony diameter (21.0 and $25.0 \mathrm{~mm}$, respectively). MC769 showed a reduction of 50\% of average colony diameter (after 9, 12, and 24 h of UV exposure), while DPS10 showed 50\% reduction after 12 and $24 \mathrm{~h}$ of UV exposure (Figure 6). 


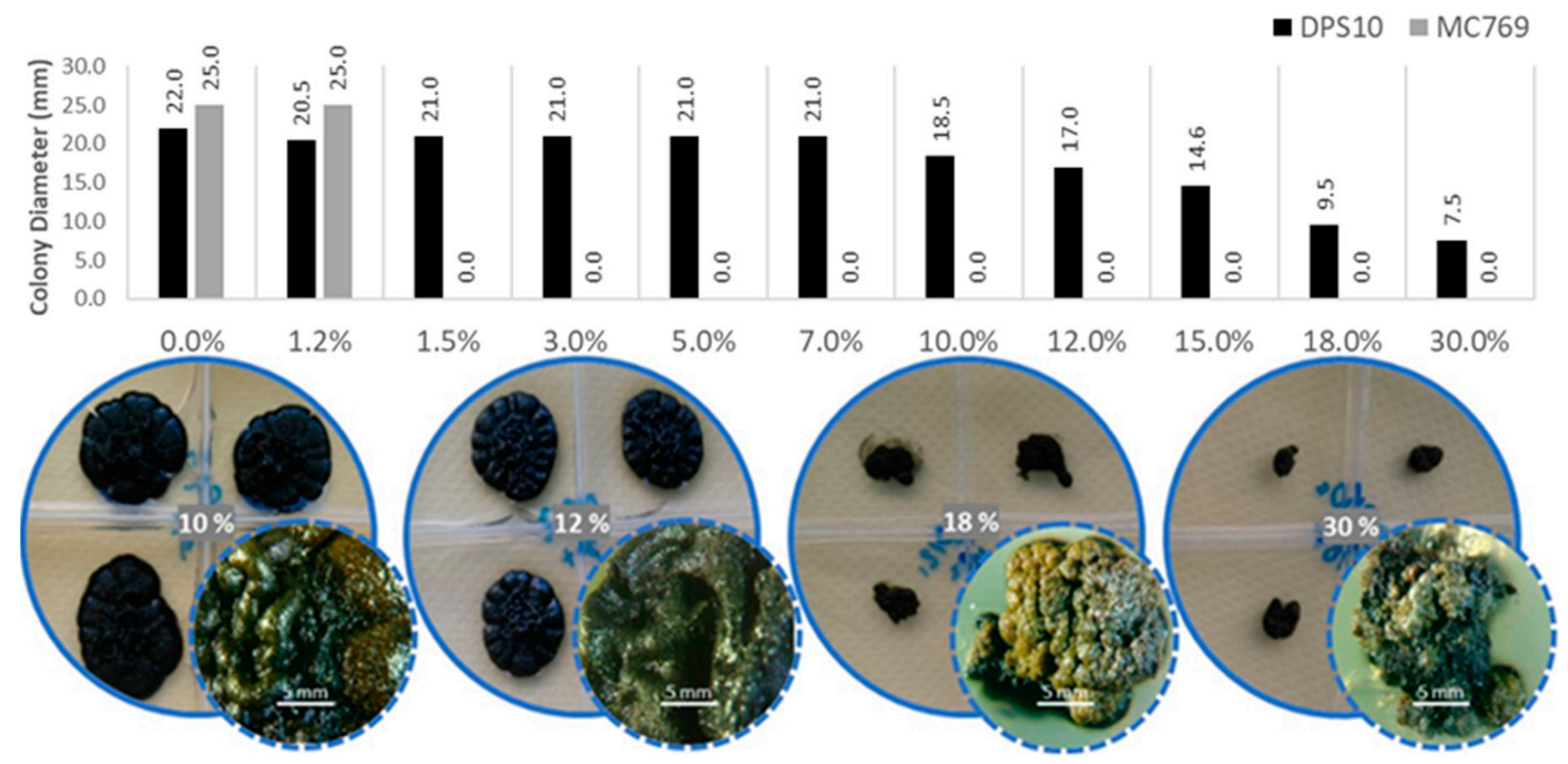

Figure 4. Salinity preferences of Pseudotaeniolina globosa DPS10 isolate shown by the colony diameter reached on MEA medium after one-month incubation at $25^{\circ} \mathrm{C}$. Column chart in the upper part exhibit comparison of DPS10 and MC769 isolates in medium supplemented with $0.0,1.2,1.5,3.0,5.0,7.0,10.0,12.0,15.0,18.0$ and $30.0 \% \mathrm{NaCl}$. Visual examination of the cultured plates in the lower part shows the growth of DPS10 isolate at 10.0,12.0, 18.0, and 30.0\% $\mathrm{NaCl}$ in quadruplicates (Petri dish of four divisions) with a stereomicroscopic focus for one of the grown colonies (bar = $5 \mathrm{~mm}$ ). Data on MC769 isolate come from De Leo et al. [16].

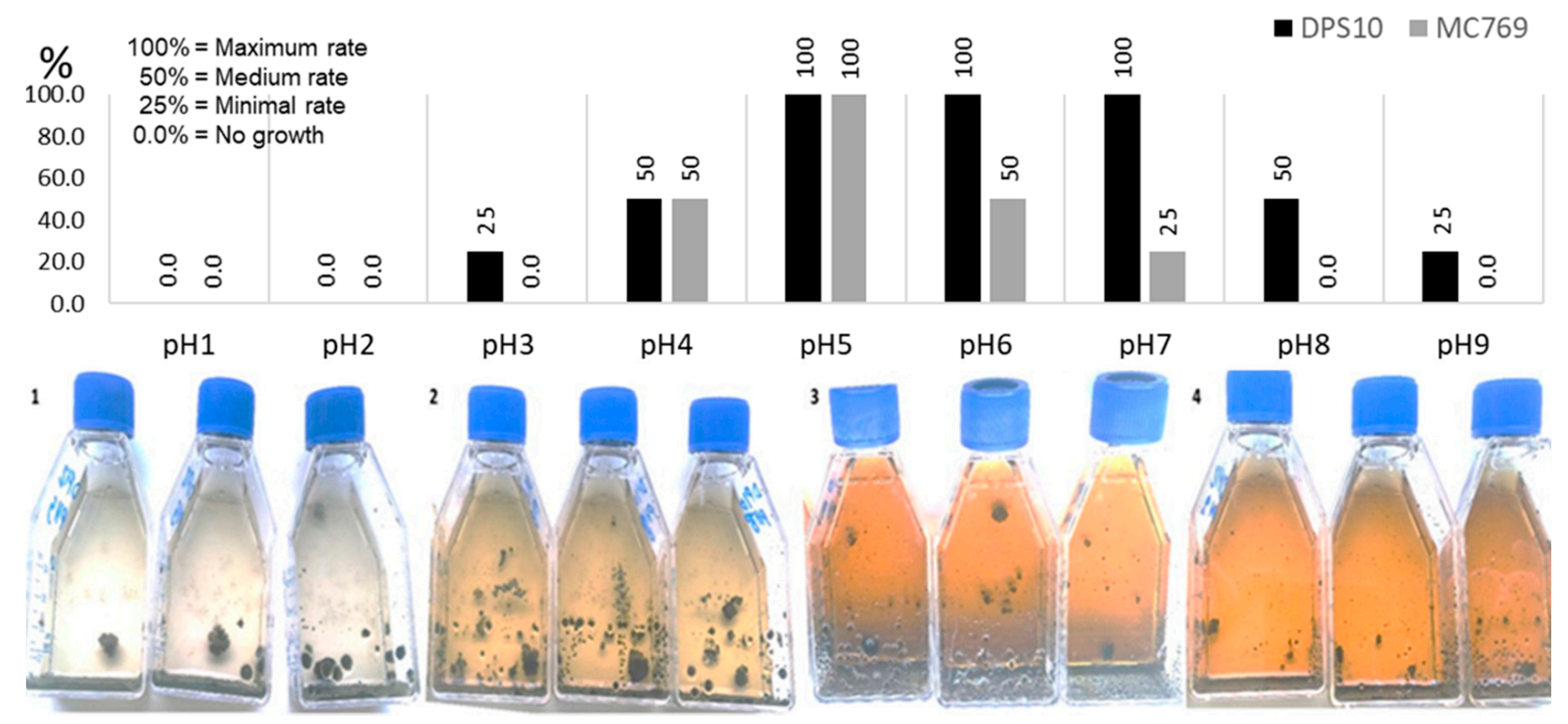

Figure 5. The $\mathrm{pH}$ growth range of Pseudotaeniolina globosa DPS10 isolate shown by four established growth grades (0.0, 25\%, $50 \%, 100 \%$ ) reached on Malt Extract Broth (MEB) medium after one-month incubation at $25^{\circ} \mathrm{C}$. Column chart in the upper part exhibits comparison of DPS10 and MC769 isolates measured at pH 1.0 to $\mathrm{pH} 9.0$. Flasks in the lower part show growth at pH 4.0 (1), pH 6.0 (2), pH 8.0 (3), and pH 9.0 (4). Data on MC769 isolate come from De Leo et al. [16]. 


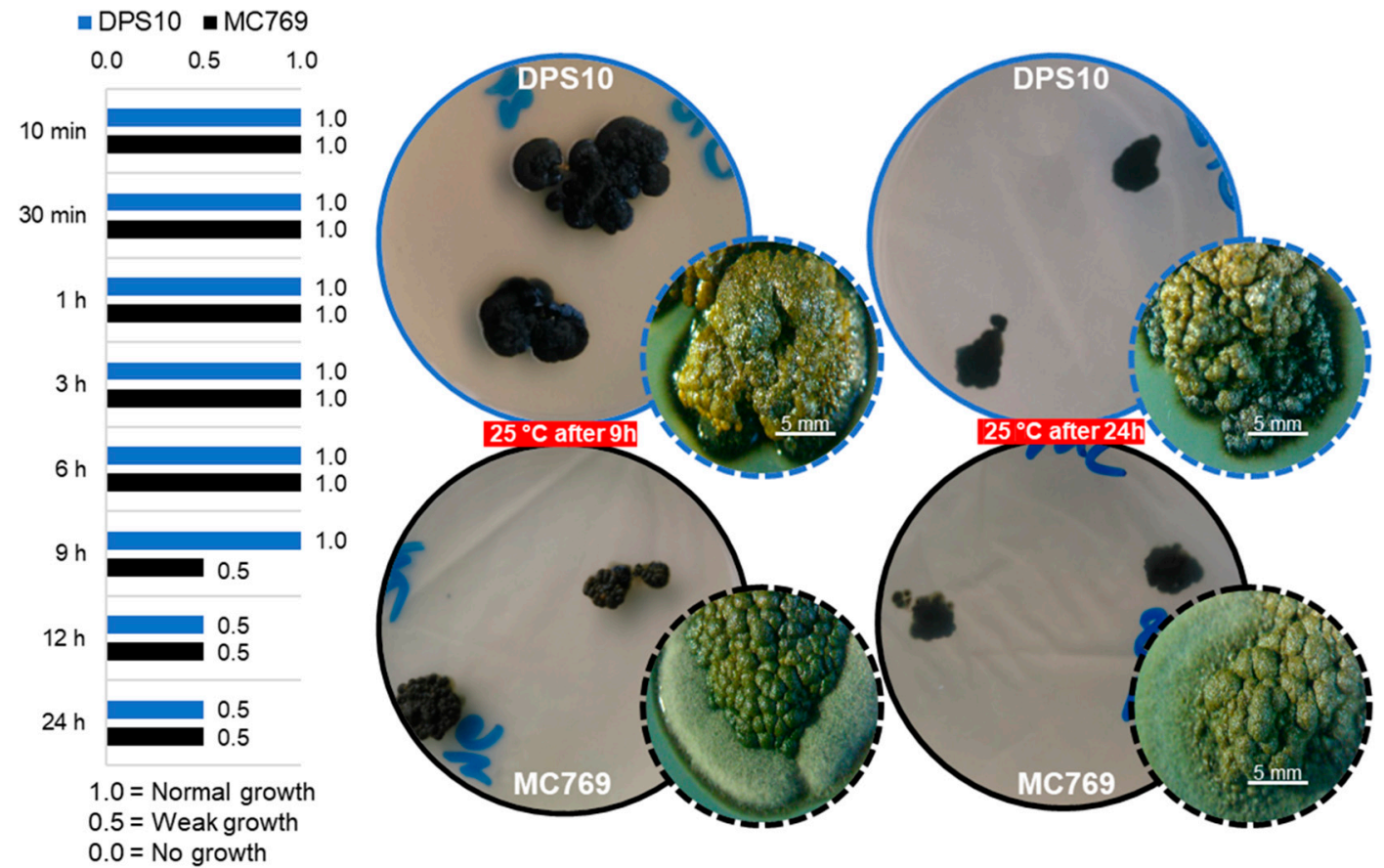

Figure 6. UV tolerance examination of Pseudotaeniolina globosa DPS10 and MC769 isolates. Column chart on the left side exhibits comparison of DPS10 and MC769 isolates growth monitored on PDA media at $25^{\circ} \mathrm{C}$ after 10 and 30 min, 1, 3, 6, 9, 12 , and $24 \mathrm{~h}$ of exposure shown by three established growth grades $(0.0,0.5,1.0)$. Visual examination of the cultured plates on the right side shows the growth of DPS10 and MC769 isolates after 9 and $24 \mathrm{~h}$, with a stereomicroscopic focus for one of the grown colonies (bar $=5 \mathrm{~mm}$ ).

\subsubsection{Heat Stress Tolerance}

Heat stress on isolates DPS10 and MC769 at 65, 70, and $75^{\circ} \mathrm{C}$ after 2 and 5 min showed the maximum growth rate a colony can reach in one month (colony diameter of 21.0 and $25.0 \mathrm{~mm}$, respectively). However, when the exposure extended to 10 and $15 \mathrm{~min}$, a lower growth rate was observed at all the tested temperatures for both isolates. At 70 and $75^{\circ} \mathrm{C}$, after $15 \mathrm{~min}$ of exposure, the MC769 showed a slower rate than the low rate described for DPS10. When the $80{ }^{\circ} \mathrm{C}$ was tested, both isolates were grown at a low rate after 2 and $5 \mathrm{~min}$ of exposure; however, only DPS10 maintained the same rate after $10 \mathrm{~min}$ and showed a slow rate after $15 \mathrm{~min}$ of exposure contrast to MC769, which showed no growth. When the $85^{\circ} \mathrm{C}$ was tested, only DPS10 grew at a slow rate after 2 and $5 \mathrm{~min}$, while showed no growth after 10 and $15 \mathrm{~min}$ of exposure (Figure 7).

\subsection{Molecular Characterization and Phylogeny of Pseudotaeniolina Globosa}

The amplification of the five loci for the two isolates was successful, showing the expected molecular size as previously reported. Sequences were deposited in GenBank repository under the accession numbers detailed in Table 2. Based on the BLAST results, similar top results were retrieved and filtered by query coverage (i.e., $<95 \%$ query coverage were discarded) and matched with "Popsets" files downloaded from the NCBI database for each locus prior to alignment and phylogenetic analysis. All the retained accessions belonged to the order Capnodiales. The maximum likelihood (ML) phylogenetic trees were rooted with the Extremaceae family species, while all the remaining sequences belonged to the families Teratosphaeriaceae and Mycosphaerellaceae for all the genotyped loci. In the case of ITS, a total of 30 accessions belonging to the order Capnodiales in addition to the current two isolates of P. globosa (DPS10 and MC769) showed an alignment length of $566 \mathrm{bp}$, including partial $5^{\prime}$ and $3^{\prime}$ ends of both ITS1 and ITS2, respectively, and the complete $5.8 \mathrm{~S}$ locus. 


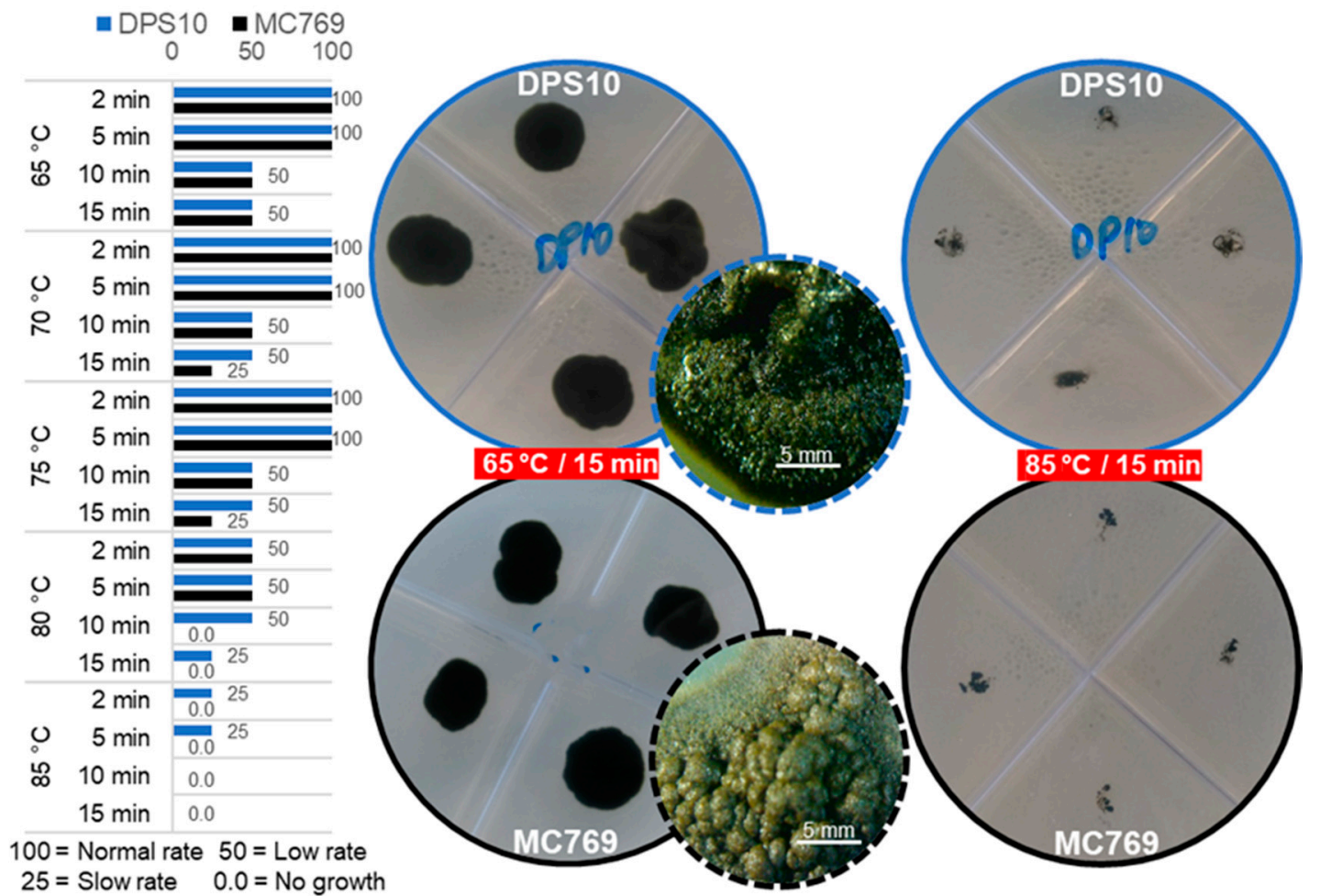

Figure 7. Heat stress tolerance examination of Pseudotaeniolina globosa DPS10 and MC769 isolates. Column chart on the left exhibits comparison of DPS10 and MC769 isolates growth monitored on PDA media after 2, 5, 10, and 15 min at 65, 70, 75,80 , and $85^{\circ} \mathrm{C}$; the $\mathrm{x}$-axis represents the grade from 100 for regular growth rate after one month of incubation (21.0 and $25.0 \mathrm{~mm}$ colony diameter for DSP10 and MC769, respectively) to 0.0 for no growth. Visual examination of the cultured plates on the right shows the growth of DPS10 and MC769 at 65 and $85^{\circ} \mathrm{C}$ after $15 \mathrm{~min}$ of heat exposure, with a stereomicroscopic focus for one of the grown colonies (bar $=5 \mathrm{~mm}$ ).

Table 2. List of Pseudotaeniolina globosa available accession numbers in the GenBank database with an indication of the literature reference where they were published.

\begin{tabular}{|c|c|c|c|c|c|c|c|}
\hline \multirow{2}{*}{ Isolate Code } & \multirow{2}{*}{$\begin{array}{l}\text { Isolation } \\
\text { Country }\end{array}$} & \multicolumn{5}{|c|}{ GenBank Accession Number } & \multirow{2}{*}{ References } \\
\hline & & ITS & nrSSU (18S) & nrLSU (28S) & BT2 & RPB2 & \\
\hline CBS $303.84 *$ & Germany & AJ244268 & - & - & - & - & [44] \\
\hline CBS 110353 & Germany & AJ $244268^{* *}$ & - & - & - & - & [45] \\
\hline MC769*** & Italy & AY128700 & NG062782 & MW367900 & MW371112 & MW371115 & [16], current study \\
\hline L10 & Austria & HQ115663 & - & - & - & - & [46] \\
\hline ICP 1002 & Austria & КС 311489 & - & - & - & - & [47] \\
\hline CCFEE 5734 & Italy & KF309976 & - & KF310010 & KF546758 & KF310073 & [21] \\
\hline H19 & Chili & KF578436 & - & - & - & & [48] \\
\hline HF24 & Austria & KR081416 & - & - & - & - & [49] \\
\hline DPS10 & Egypt & MH396690 & MH396869 & МH396691 & MW371113 & MW371114 & Current study \\
\hline
\end{tabular}

* Initially identified as Trimmatostroma sp; ** No sequences were reported; however, the cited reference was reported as similar to CBS $303.84 ;{ }^{* * *}$ First report and description of the species; the isolate also recorded as CBS $109889^{\mathrm{T}}$.

The number of identical sites was $253 \mathrm{bp}(50 \%)$, while the un-gapped average length was $446 \mathrm{bp}$ with $\mathrm{GC} \%=55.9 \%$. A major observation is that the family Teratosphaeriaceae members were highly clustered into two sub-clades (I and II; bootstrap value $\geq 0.80$ ). The isolate P. globosa DPS10 was highly clustered to eight $P$. globosa accessions (bootstrap value $=0.96$ ). The most similar sequence to the Egyptian isolate (with bootstrap value $=0.81$ ) was the specimen CBS303.84, which was early registered in GenBank as Trimmatostroma sp. [44] and corrected to P. globosa in a later publication [8]. The geolocation of the samples (Table 2) does not reflect the phylogenetic relationships based on this marker (Figure 8, ITS). 

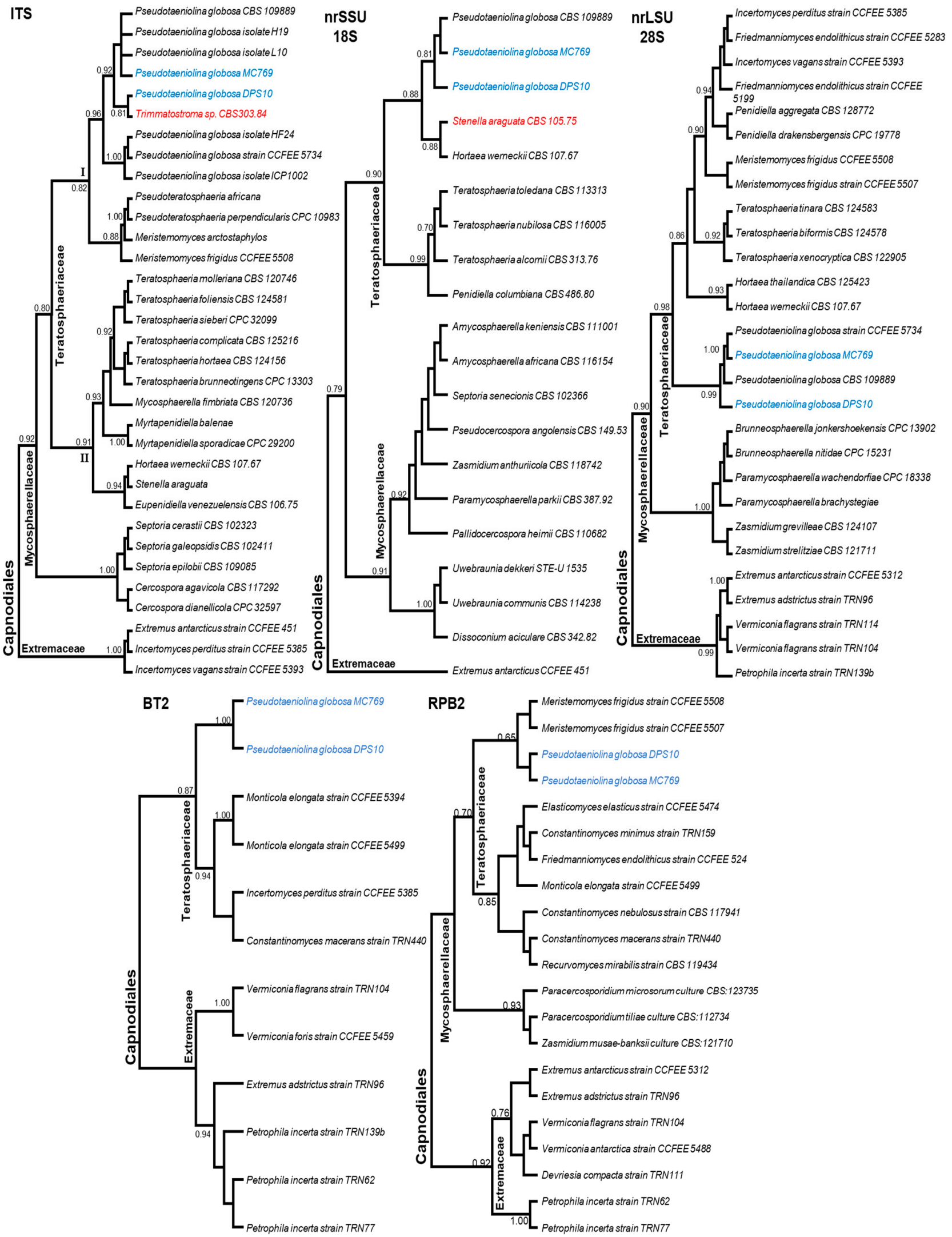

Figure 8. Maximum likelihood-based phylogenetic trees for top similar accessions of Extremaceae, Mycosphaerellaceae, and Teratosphaeriaceae families (order Capnodiales) from GenBank NCBI database to ITS, nrSSU 18S, nrLSU 28S, BT2 and RPB2 sequences of Pseudotaeniolina globosa isolates (MC769 and DPS10 written in blue color). Trees are rooted by the Extremaceae clade/species; mistakenly labeled/grouped accessions are written in red. 
In the case of the nrSSU (18S), a total of 18 accessions belonging to the order Capnodiales in addition to the current two isolates of P. globosa (DPS10 and MC769) showed an alignment length of $1670 \mathrm{bp}$. The number of identical sites was $1541 \mathrm{bp}(92.3 \%)$, while the un-gapped average length was $1667 \mathrm{bp}$ with GC\% $=48.5 \%$. The P. globosa isolates were included within the clades identified as order Capnodiales. In addition to DPS10 and MC769 isolates, a single P. globosa accession CCFEE 5734 was highly clustered in the same clade (bootstrap value $=0.92$ ). The $P$. globosa accessions were sister to Hortaea werneckii (Horta) Nishim. \& Miyaji (CBS 107.67), a very peculiar species known as an extremophilic halotolerant fungus, and Stenella araguata Syd. (CBS 105.75) (family Mycosphaerellaceae) a biological causal agent for Tinea nigra dermatological disease (bootstrap value $=0.79$; Figure 8, nrSSU 18S) [50]. For the nrLSU (28S), a total of 28 accessions in addition to the current two isolates of P. globosa (DPS10 and MC769) showed an alignment length of $782 \mathrm{bp}$ (incomplete sequence, partial at $3^{\prime}$ terminal). The number of identical sites was $573 \mathrm{bp}(73.8 \%)$, while the un-gapped average length was $760 \mathrm{bp}$ with GC $\%=53.9 \%$. The ML tree showed a monophyletic clustering of the families within order Capnodiales with the Extremaceae clade as root, followed by the Mycosphaerellaceae clade and the Teratosphaeriaceae clade. In the latter, the P. globosa DPS10 and MC769 isolates were highly clustered with two P. globosa accessions recorded as Capnodiales incertae sedis (bootstrap value $=0.99$; Figure 8 , nrLSU 28S).

Based on BT2, all retrieved sequences by BLAST without the intronic regions were discarded. A total of nine accessions and the current two isolates of P. globosa (DPS10 and MC769) showed an alignment length of $425 \mathrm{bp}$. The number of identical sites was $197 \mathrm{bp}(48.2 \%)$, while the un-gapped average length was $385 \mathrm{bp}$ with GC $\%=55.6 \%$. The isolates of $P$. globosa were included within the clades identified as order Capnodiales, family Teratosphaeriaceae (Figure 8, BT2). In RPB2, a total of 19 accessions and the current two isolates of P. globosa (DPS10 and MC769) showed an alignment length of $239 \mathrm{bp}$. The number of identical sites was $107 \mathrm{bp}(44.8 \%)$, while the un-gapped average length was $239 \mathrm{bp}$ with GC\% $=53.1 \%$. The isolates of $P$. globosa were included within the clades identified as order Capnodiales, family Teratosphaeriaceae with bootstrap value $=0.70$ (Figure 8, RPB2).

\section{Discussion}

Black meristematic fungi or RIFs are remarkably extremotolerant microorganisms, frequently isolated from stone surfaces and habitats where minimal nutrients are available [51]. RIF survive under extreme conditions and grow to form micro-colonial fungal life forms (MCF) [52]. The selective pressure of such harsh conditions directed the evolution of their genomes to develop tolerant alleles through adaptive genetic variation and accumulation of beneficial mutations; the genetic pools of those organisms deviated significantly from sister fungal lineages to overcome the rock surface conditions (e.g., high UV radiation and temperatures) [53]. For instance, the highly concentrated black pigments in the MCF cell walls serve as a UV-protective substance (e.g., [54]).

This is the first report of Pseudotaeniolina globosa on Egyptian archaeological remains. Pseudotaeniolina globosa is one of the uncommonly recorded RIF; only a few records were previously reported. All the reported isolates are known as environmental saprobes, predominantly found in water-limited ecological niches. Except for a unique strain isolated from the aortic wall of a patient with an aortic aneurysm, its clinical significance has not been confirmed [45].

In the current work, the morphological measurements of the hyphal length and width on MEA media of DPS10 isolate $(7.0-12.0 \times 4.0-6.0 \mu \mathrm{m})$ were smaller than the MC769 $(8.0-15.0 \times 6.0-7.0 \mu \mathrm{m})$ [16]. However, the DPS10 produces single cells or asymmetrically septate cells after conidiogenesis, a unique character to $P$. globosa [16]. The current isolate is slimy and forms yeast-like colonies after 4-5 days of growth, which differentiate the P. globosa from a micro-morphologically similar species known as Knufia petricola (Wollenz. \& de Hoog) Gorbushina \& Gueidan (=Sarcinomyces petricola Wollenz. \& de Hoog) [16,55,56]. Regardless 
of the morphological variation between both isolates, the molecular characterization of the DPS10 isolate confirms its identity and high similarity to the P. globosa MC769 isolate. However, under abiotic stress ( $\mathrm{pH}$, salinity, and temperature) the DPS10 showed tolerance to extreme conditions.

The $\mathrm{pH}$ of a medium is a decisive factor for fungal presence and diversity; for example, the soil $\mathrm{pH}$ was the most significant factor correlated to the fungal community composition in Svalbard, High Arctic [57]. The DPS10 optimum growth was at 5.0-7.0 pH and it grew on a broader range from 3.0 to $9.0 \mathrm{pH}$ compared to MC769 isolate, which grew well between 4.0-6.0 and scarcely at $7.0 \mathrm{pH}$. Thus, the ability of DPS10 to colonize different media with different $\mathrm{pH}$ ranges is worth further studying.

The DPS10 optimum growth was at $0.25 \mathrm{M}(1.5 \%) \mathrm{NaCl}$ and growth continued, although at lower rates, up to $5.2 \mathrm{M}(30.0 \%) \mathrm{NaCl}$, while $\mathrm{MC7} 69$ was strictly limited to $0.20 \mathrm{M}(1.2 \%) \mathrm{NaCl}$ supplemented MEA. Fungi are considered halophilic if they are isolated from sites with $1.7 \mathrm{M}(\sim 10.0 \%) \mathrm{NaCl}$, and halotolerant if sporadic isolates can grow in vitro at $3 \mathrm{M} \mathrm{NaCl}$ supplemented medium [58]. According to previous reports of model halotolerant fungi, Debaryomyces hansenii (Zopf) Lodder \& Kreger-van Rij can grow in up to $3 \mathrm{M} \mathrm{NaCl}$ [59], Hortaea werneckii in up to $5 \mathrm{M} \mathrm{NaCl}$ [60], while Wallemia ichthyophaga Johan-Olsen thrives in $5.2 \mathrm{M} \mathrm{NaCl}$, the latter of which is considered the most halophilic fungus; however, it is unable to grow without salt in its medium [61]. The MC769 isolate was previously described as halo-sensitive [16]. However, according to our results, the DPS10 isolate can be considered halotolerant [58]. At the intracellular $\mathrm{Na}^{+}$and $\mathrm{K}^{+}$ion accumulation level, it was shown that D. hansenii and $W$. ichthyophaga are $\mathrm{Na}^{+}$-intruder fungi and accumulate higher amounts of $\mathrm{Na}^{+}$ions than $H$. werneckii, which excludes these ions from its cells [58]. Halophily is expressed in several groups of the same order, but not the closest at the taxonomic level [58]. Hortaea werneckii is the nearest phylogenetic neighbor to P. globosa and, most probably, follows the same mechanism. Alternatively, they are extreme xerotolerants whose growth on substrates is determined by water potential and not by the solute's chemical nature [62].

DPS10 and MC769 showed optimum growth rate at $25^{\circ} \mathrm{C}$, but DPS10 had a broader range of growth temperatures $\left(4-37^{\circ} \mathrm{C}\right)$ than $\mathrm{MC} 769\left(10-30^{\circ} \mathrm{C}\right)$. Additionally, DPS10 isolate was able to regrow after being exposed to $85^{\circ} \mathrm{C}$ for 5 min while MC769 regrow only after being exposed to $80^{\circ} \mathrm{C}$ for $5 \mathrm{~min}$. Both $P$. globosa isolates are melanized, thus constitute a chemical ability to absorb and tolerate UV light [63]. Both isolates were tolerant to UV exposure up to $24 \mathrm{~h}$; however, the growth rate was not affected up to $9 \mathrm{~h}$ in the DPS10 case compared to MC769, which was affected after $9 \mathrm{~h}$ of exposure to UV. Melanin serves as an extracellular electron-dense granular layer for black fungi and yeasts and forms an intracolonial matrix structure [52]. The results suggest that DPS10 is an extremotolerant P. globosa ecotype adapted to the harsh and extreme environments as arid and desert climate. It can survive $\mathrm{pH}$ changes, high salt concentrations, and tolerate high temperatures and UV radiation, demonstrating its potential as a persistent bio-deteriorating biological agent. Thus, further studies are required to understand its nature fully and develop counter strategies and conservation plans for one of Egypt's oldest pyramids (i.e., the Djoser pyramid).

Within Ascomycota, the main orders with halophilic and halotolerant representatives are Capnodiales, Dothideales, and Eurotiales [58]. Among them, the Capnodiales have a xero-tolerant tendency, as they contain a large number of extremotolerant species that can grow as epilithic or crypto-endolithic species at high or low temperatures [6]. Most RIF possesses convergent morphological and physiological characteristics; however, many RIF subgroups are phylogenetically uncertain within the class Dothideomycetes [3]. According to the NCBI taxonomy database, the genus Pseudotaeniolina is uncertainly positioned within the order Capnodiales (incertae sedis) with no family assigned. When first reported, P. globosa was found clustered with species associated with low water availability (halophilic, epilithic, or epiphytic) and defined as RIF within the Dothideales but was poorly supported by the phylogenetic analysis using ITS sequences (>50\%) [16]. In the current study, based 
on five molecular markers (ITS, SSU, LSU, BT2, and RPB2), P. globosa was clustered within the Teratosphaeriaceae family with bootstrap values of 0.70-0.98.

Ruibal et al. [3] conducted a phylogenetic analysis using a multi-locus approach (nrSSU, nrLSU, and mtSSU) to resolve several taxonomic complexes of Dothideomycetes families. Among other families, the Teratosphaeriaceae was the most diverse and phylogenetically conflicting. The family Teratosphaeriaceae was represented as two separated clades, numbered as (1) and (2); however, the study did not include any P. globosa records. When we matched the species, the P. globosa isolates should be part of Teratosphaeriaceae group 1. When locus analyses conducted separately, the clustering was apparent at the ribosomal cistron sequences (ITS, SSU, and LSU) and resulted in a better resolution for the family compared to the closest one (Mycosphaerellaceae), especially the LSU. In contrast to other markers, the SSU phylogenetic signal was the only marker to show a paraphyletic clustering among the two proximate families, Mycosphaerellaceae and Teratosphaeriaceae; however, the taxonomical resolution within the Teratosphaeriaceae was not as structured as the ITS based phylogeny. The current study focused on the taxonomical family assignment of the P. globosa rather than on the taxonomical analysis of the order or on finding the best marker for such an assignment. However, many accessions were discarded and are missing in our analysis (e.g., RPB2) due to wrong taxonomic assignment or incomplete metadata about the accessions, which require urgent revision to avoid misleading phylogenetic signals. For instance, the P. globosa CCFEE 5734 RPB2 sequence (GenBank accessions KF310073) seems confused with Extremus antarcticus Quaedvl. \& Crous isolate CCFEE 451 RPB2 sequence (GenBank accessions KF310085 [21]).

Future research will target the genomic signatures of the extremo-tolerance characters of the DPS10 isolate to accurately detect the transcriptional responses and metabolic suspension and reactivation under the fluctuation of water availability and its extreme ability to maintain viability in a high salinity medium. This will be achievable after acquiring additional $P$. globosa isolates and performing a more sophisticated comparison at genomic, transcriptomic, and metabolic levels using NGS-based approaches.

Author Contributions: Conceptualization, S.M.R., F.D.L. and C.U.; methodology, S.M.R., F.D.L. and M.M.; software, M.M.; validation, S.M.R.; formal analysis, S.M.R. and M.M.; investigation, S.M.R.; resources, M.M., M.A.-S.R., R.M.R., O.W. and C.U.; data curation, S.M.R. and M.M.; writing-original draft preparation, S.M.R. and M.M.; writing-review and editing, R.M.R., O.W., C.U., F.D.L. and M.A.-S.R.; supervision, M.A.-S.R., R.M.R., O.W. and C.U.; funding acquisition, M.A.-S.R. and M.M. All authors have read and agreed to the published version of the manuscript.

Funding: Samah Rizk was supported by a Ph.D. scholarship funded by the Erasmus Mundus Action 2: EMMAG Programme (2014-2016) and the experiments were funded by Science, Technology \& Innovation Funding Authority (STDF) under grant 26383 (2018-2020).

Institutional Review Board Statement: Not applicable.

Informed Consent Statement: Not applicable.

Data Availability Statement: Sequences were deposited in GenBank repository under the accession numbers detailed in Table 2.

Conflicts of Interest: The authors declare no conflict of interest.

\section{References}

1. Staley, J.T.; Palmer, F.; Adams, J.B. Microcolonial fungi: Common inhabitants on desert rocks? Science 1982, 215, 1093-1095. [CrossRef] [PubMed]

2. Wollenzien, U.; de Hoog, G.S.; Krumbein, W.E.; Urzí, C. On the isolation of microcolonial fungi occurring on and in marble and other calcareous rocks. Sci. Total Environ. 1995, 167, 287-294. [CrossRef]

3. Ruibal, C.; Gueidan, C.; Selbmann, L.; Gorbushina, A.A.; Crous, P.W.; Groenewald, J.Z.; Muggia, L.; Grube, M.; Isola, D.; Schoch, C.L.; et al. Phylogeny of rock-inhabiting fungi related to Dothideomycetes. Stud. Mycol. 2009, 64, 123-133. [CrossRef] [PubMed]

4. Sterflinger, K. Fungi as geologic agents. Geomicrobiol. J. 2000, 17, 97-124. [CrossRef]

5. Gorbushina, A.A. Life on the rocks: Life on the rocks. Environ. Microbiol. 2007, 9, 1613-1631. [CrossRef] [PubMed] 
6. Selbmann, L.; de Hoog, G.S.; Mazzaglia, A.; Friedmann, E.I.; Onofri, S. Fungi at the edge of life: Cryptoendolithic black fungi from Antarctic desert. Stud. Mycol. 2005, 51, 1-32.

7. Sterflinger, K. Black yeasts and meristematic fungi: Ecology, diversity and identification. In Biodiversity and Ecophysiology of Yeasts; Rosa, C.A., Péter, G., Eds.; Springer: Berlin/Heidelberg, Germany, 2006; pp. 501-514.

8. Selbmann, L.; de Hoog, G.S.; Zucconi, L.; Isola, D.; Ruisi, S.; van den Ende, A.H.G.G.; Ruibal, C.; De Leo, F.; Urzì, C.; Onofri, S. Drought meets acid: Three new genera in a dothidealean clade of extremotolerant fungi. Stud. Mycol. 2008, 61, 1-20. [CrossRef]

9. Sert, H.B.; Sterflinger, K. A new Coniosporium species from historical marble monuments. Mycol. Prog. 2010, 9, 353-359. [CrossRef]

10. Sert, H.B.; Sümbül, H.; Sterflinger, K. Microcolonial fungi from antique marbles in Perge/Side/Termessos (Antalya/Turkey). Antonie Van Leeuwenhoek 2007, 91, 217-227. [CrossRef]

11. Marvasi, M.; Donnarumma, F.; Frandi, A.; Mastromei, G.; Sterflinger, K.; Tiano, P.; Perito, B. Black microcolonial fungi as deteriogens of two famous marble statues in Florence, Italy. Int. Biodeterior. Biodegrad. 2012, 68, 36-44. [CrossRef]

12. Isola, D.; Selbmann, L.; de Hoog, G.S.; Fenice, M.; Onofri, S.; Prenafeta-Boldú, F.X.; Zucconi, L. Isolation and screening of black fungi as degraders of volatile aromatic hydrocarbons. Mycopathologia 2013, 175, 369-379. [CrossRef] [PubMed]

13. Isola, D.; Zucconi, L.; Onofri, S.; Caneva, G.; de Hoog, G.S.; Selbmann, L. Extremotolerant rock inhabiting black fungi from Italian monumental sites. Fungal Divers. 2016, 76, 75-96. [CrossRef]

14. De Leo, F.; Urzì, C. Microfungi from deteriorated materials of cultural heritage. In Fungi from Different Substrates; Misra, J.K., Tewari, J.P., Deshmukh, S.K., Vágvölgyi, C., Eds.; CRC Press: Boca Ratón, FL, USA, 2015; pp. 144-158.

15. Salvadori, O.; Municchia, A.C. The role of fungi and lichens in the biodeterioration of stone monuments. Open Conf. Proc. J. 2016, 7, 39-54. [CrossRef]

16. De Leo, F.; Urzì, C.; de Hoog, G.S. A new meristematic fungus, Pseudotaeniolina globosa. Antonie Van Leeuwenhoek 2003, 83, 351-360. [CrossRef] [PubMed]

17. Zucconi, L.; Gagliardi, M.; Isola, D.; Onofri, S.; Andaloro, M.C.; Pelosi, C.; Pogliani, P.; Selbmann, L. Biodeterioration agents dwelling in or on the wall paintings of the Holy Saviour's cave (Vallerano, Italy). Int. Biodeterior. Biodegrad. 2012, 70, 40-46. [CrossRef]

18. Onofri, S.; Zucconi, L.; Isola, D.; Selbmann, L. Rock-inhabiting fungi and their role in deterioration of stone monuments in the Mediterranean area. Plant Biosyst. 2014, 148, 384-391. [CrossRef]

19. De Leo, F.; Antonelli, F.; Pietrini, A.M.; Ricci, S.; Urzì, C. Study of the euendolithic activity of blackmeristematic fungi isolated from a marble statue in the Quirinale Palace's Gardens in Rome, Italy. Facies 2019, 65, 18. [CrossRef]

20. De Leo, F.; Lo Giudice, A.; Alaimo, C.; De Carlo, G.; Rappazzo, A.C.; Graziano, M.; De Domenico, E.; Urzì, C. Occurrence of the black yeast Hortaea werneckii in the Mediterranean Sea. Extremophiles 2019, 23, 9-17. [CrossRef]

21. Egidi, E.; de Hoog, G.S.; Isola, D.; Onofri, S.; Quaedvlieg, W.; de Vries, M.; Verkley, G.J.M.; Stielow, J.B.; Zucconi, L.; Selbmann, L. Phylogeny and taxonomy of meristematic rock-inhabiting black fungi in the Dothideomycetes based on multi-locus phylogenies. Fungal Divers. 2014, 65, 127-165. [CrossRef]

22. Sterflinger, K.; de Hoog, G.S.; Haase, G. Phylogeny and ecology of meristematic ascomycetes. Stud. Mycol. 1999, 43, 5-22.

23. Ruibal, C.; Platas, G.; Bills, G.F. Isolation and characterization of melanized fungi from limestone formations in Mallorca. Mycol. Prog. 2005, 4, 23-38. [CrossRef]

24. Ruibal, C.; Platas, G.; Bills, G.F. High diversity and morphological convergence among melanised fungi from rock formations in the Central Mountain System of Spain. Pers. Mol. Phylogeny Evol. Fungi 2008, 21, 93-110. [CrossRef] [PubMed]

25. Ruibal Villaseñor, C. Isolation and Characterization of Melanized, Slow-Growing Fungi from Semiarid Rock Surfaces of Central Spain and Mallorca. Ph.D. Thesis, Universidad Autónoma de Madrid, Madrid, Spain, 2004.

26. Gueidan, C.; Savić, S.; Thüs, H.; Roux, C.; Keller, C.; Tibell, L.; Prieto, M.; Heiðmarsson, S.; Breuss, O.; Orange, A.; et al. Generic classification of the Verrucariaceae (Ascomycota) based on molecular and morphological evidence: Recent progress and remaining challenges. Taxon 2009, 58, 184-208. [CrossRef]

27. Roskov, Y.; Ower, G.; Orrell, T.; Nicolson, D.; Bailly, N.; Kirk, P.M.; Bourgoin, T.; DeWalt, R.E.; Decock, W.; Nieukerken, E.V.; et al. Species 2000 E ITIS Catalogue of Life, 2019 Annual Checkist; Species 2000; Naturalis: Leiden, The Netherlands, 2020; Available online: www.catalogueoflife.org/annual-checklist/2019 (accessed on 10 October 2020).

28. Afifi, H.; Geweely, N. Comparative study on fungal deterioration and ozone conservation of El-Anfoushi and Al-Shatby Archeological Tombs-Alexandria-Egypt. J. Am. Sci. 2011, 7, 776-784. [CrossRef]

29. Mansour, M.; Ahmed, H. Occurrence of fungi on some deteriorated ancient Egyptian materials and their controlling by ecofriendly products. Egypt. J. Archaeol. Restor. Stud. 2012, 2, 91-101. [CrossRef]

30. Mohamed, S.S.; Ibrahim, S.E. Characterization and management of fungal deterioration of ancient limestone at different sites along Egypt. Egypt. J. Microbiol. 2018, 53, 177-191. [CrossRef]

31. Kane, J.; Summerbell, R.C. Sodium chloride as aid in identification of Phaeoannellomyces werneckii and other medically important dematiaceous fungi. J. Clin. Microbiol. 1987, 25, 944-946. [CrossRef]

32. Küster, F.W.; Thiel, A. Tabelle per le Analisi Chimiche e Chimico-Fisiche, 14th ed.; HOEPLI: Milano, Italy, 1999.

33. Möller, E.M.; Bahnweg, G.; Sandermann, H.; Geiger, H.H. A simple and efficient protocol for isolation of high molecular weight DNA from filamentous fungi, fruit bodies, and infected plant tissues. Nucleic Acids Res. 1992, 20, 6115-6116. [CrossRef] 
34. Urzì, C.; De Leo, F.; Lo Passo, C.; Criseo, G. Intra-specific diversity of Aureobasidium pullulans strains isolated from rocks and other habitats assessed by physiological methods and by random amplified polymorphic DNA (RAPD). J. Microbiol. Methods 1999, 36, 95-105. [CrossRef]

35. Kearse, M.; Moir, R.; Wilson, A.; Stones-Havas, S.; Cheung, M.; Sturrock, S.; Buxton, S.; Cooper, A.; Markowitz, S.; Duran, C.; et al. Geneious basic: An integrated and extendable desktop software platform for the organization and analysis of sequence data. Bioinformatics 2012, 28, 1647-1649. [CrossRef]

36. Thompson, J.D.; Higgins, D.G.; Gibson, T.J. CLUSTAL W: Improving the sensitivity of progressive multiple sequence alignment through sequence weighting, position-specific gap penalties and weight matrix choice. Nucleic Acids Res. 1994, 22, 4673-4680. [CrossRef] [PubMed]

37. Price, M.N.; Dehal, P.S.; Arkin, A.P. FastTree 2-Approximately maximum-likelihood trees for large alignments. PLoS ONE 2010, 5, e9490. [CrossRef] [PubMed]

38. White, T.J.; Bruns, T.; Lee, S.; Taylor, J.W. Amplification and direct sequencing of fungal ribosomal RNA genes for phylogenetics. In PCR Protocols: A Guide to Methods and Applications; Innis, M.A., Gelfand, D.H., Sninsky, J.J., White, T.J., Eds.; Academic Press: New York, NY, USA, 1990; pp. 315-322.

39. Crous, P.W.; Schoch, C.L.; Hyde, K.D.; Wood, A.R.; Gueidan, C.; de Hoog, G.S.; Groenewald, J.Z. Phylogenetic lineages in the Capnodiales. Stud. Mycol. 2009, 64, 17-47. [CrossRef] [PubMed]

40. Vilgalys, R.; Hester, M. Rapid genetic identification and mapping of enzymatically amplified ribosomal DNA from several Cryptococcus species. J. Bacteriol. 1990, 172, 4238-4246. [CrossRef] [PubMed]

41. O'Donnell, K.; Cigelnik, E. Two divergent intragenomic rDNA ITS2 types within a monophyletic lineage of the fungus Fusarium are nonorthologous. Mol. Phylogenet. Evol. 1997, 7, 103-116. [CrossRef] [PubMed]

42. Liu, Y.J.; Whelen, S.; Hall, B.D. Phylogenetic relationships among ascomycetes: Evidence from an RNA polymerse II subunit. Mol. Biol. Evol. 1999, 16, 1799-1808. [CrossRef]

43. Quaedvlieg, W.; Kema, G.H.J.; Groenewald, J.Z.; Verkley, G.J.M.; Seifbarghi, S.; Razavi, M.; Gohari, A.M.; Mehrabi, R.; Crous, P.W. Zymoseptoria gen. nov.: A new genus to accommodate Septoria-like species occurring on Graminicolous hosts. Pers. Mol. Phylogeny Evol. Fungi 2011, 26, 57-69. [CrossRef]

44. de Hoog, S.; Zalar, P.; Urzì, C.; De Leo, F.; Yurlova, N.; Sterflinger, K. Relationships of dothideaceous black yeasts and meristematic fungi based on 5.8S and ITS2 rDNA sequence comparison. Stud. Mycol. 1999, 43, 31-37.

45. Kurzai, O.; Keith, P.; Hoog, S.; Abele-Horn, M.; Frosch, M. Postmortem isolation of Pseudotaeniolina globosa from a patient with aortic aneurysm. Mycoses 2003, 46, 141-144. [CrossRef]

46. Gorfer, M.; Blumhoff, M.; Klaubauf, S.; Urban, A.; Inselsbacher, E.; Bandian, D.; Mitter, B.; Sessitsch, A.; Wanek, W.; Strauss, J. Community profiling and gene expression of fungal assimilatory nitrate reductases in agricultural soil. ISME J. 2011, 5, 1771-1783. [CrossRef]

47. Gorfer, M.; Klaubauf, S.; Berger, H.; Strauss, J. The fungal contribution to the nitrogen cycle in agricultural soils. In Metagenomics of the Microbial Nitrogen Cycle: Theory, Methods and Applications; Marco, D., Ed.; Caister Academic Press: Córdoba, Argentina, 2014; pp. 209-225.

48. Ortiz, R.; Navarrete, H.; Navarrete, J.; Párraga, M.; Carrasco, I.; de la Vega, E.; Ortiz, M.; Herrera, P.; Blanchette, R.A. Deterioration, decay and identification of fungi isolated from wooden structures at the Humberstone and Santa Laura saltpeter works: A world heritage site in Chile. Int. Biodeterior. Biodegrad. 2014, 86, 309-316. [CrossRef]

49. Piñar, G.; Dalnodar, D.; Voitl, C.; Reschreiter, H.; Sterflinger, K. Biodeterioration risk threatens the 3100 year old staircase of Hallstatt (Austria): Possible involvement of halophilic microorganisms. PLoS ONE 2016, 11, e0148279. [CrossRef] [PubMed]

50. Perez, C.; Colella, M.T.; Olaizola, C.; de Capriles, C.H.; Magaldi, S.; Mata-Essayag, S. Tinea Nigra: Report of twelve cases in Venezuela. Mycopathologia 2005, 160, 235-238. [CrossRef] [PubMed]

51. Urzì, C.; De Leo, F.; De Hoog, S.; Sterflinger, K. Recent advances in the molecular biology and ecophysiology of meristematic stone-inhabiting fungi. In Of Microbes and Art: The role of Microbial Communities in the Degradation and Protection of Cultural Heritage; Ciferri, O., Tiano, P., Mastromei, G., Eds.; Springer: Boston, MA, USA, 2000; pp. 3-19.

52. Gorbushina, A. Microcolonial fungi: Survival potential of terrestrial vegetative structures. Astrobiology 2003, 3, 543-554. [CrossRef]

53. Ametrano, C.G.; Muggia, L.; Grube, M. Extremotolerant black fungi from rocks and lichens. In Fungi in Extreme Environments: Ecological Role and Biotechnological Significance; Tiquia-Arashiro, S.M., Grube, M., Eds.; Springer: Cham, Switzerland, 2019 ; pp. 119-143.

54. Urzì, C.; Wollenzien, U.; Criseo, G.; Krumbein, W.E. Biodiversity of the rock inhabiting microflora with special reference to black fungi and black yeasts. Microb. Divers. Ecosyst. Funct. 1995, 16, 289-302.

55. Wollenzien, U.; de Hoog, G.S.; Krumbein, W.; Uijthof, J.M.J. Sarcinomyces petricola, a new microcolonial fungus from marble in the Mediterranean basin. Antonie Van Leeuwenhoek 1997, 71, 281-288. [CrossRef]

56. Tsuneda, A.; Hambleton, S.; Currah, R.S. The Anamorph Genus Knufia and its phylogenetically allied species in Coniosporium, Sarcinomyces, and Phaeococcomyces. Botany 2011, 89, 523-536. [CrossRef]

57. Kaštovská, K.; Elster, J.; Stibal, M.; Šantrůčková, H. Microbial assemblages in soil microbial succession after glacial retreat in Svalbard (High Arctic). Microb. Ecol. 2005, 50, 396. [CrossRef]

58. Gunde-Cimerman, N.; Ramos, J.; Plemenitaš, A. Halotolerant and halophilic fungi. Mycol. Res. 2009, 113, 1231-1241. [CrossRef]

59. Prista, C.; Loureiro-Dias, M.C.; Montiel, V.; García, R.; Ramos, J. Mechanisms underlying the halotolerant way of Debaryomyces hansenii. FEMS Yeast Res. 2005, 5, 693-701. [CrossRef] 
60. Plemenitaš, A.; Vaupotič, T.; Lenassi, M.; Kogej, T.; Gunde-Cimerman, N. Adaptation of extremely halotolerant black yeast Hortaea werneckii to increased osmolarity: A molecular perspective at a glance. Stud. Mycol. 2008, 61, 67-75. [CrossRef] [PubMed]

61. Zalar, P.; Sybren de Hoog, G.; Schroers, H.-J.; Frank, J.M.; Gunde-Cimerman, N. Taxonomy and phylogeny of the xerophilic genus Wallemia (Wallemiomycetes and Wallemiales, cl. et ord. nov.). Antonie Van Leeuwenhoek 2005, 87, 311-328. [CrossRef] [PubMed]

62. Pitt, J.I.; Hocking, A.D. Fungi and Food Spoilage, 3rd ed.; Springer: Dordrecht, The Netherlands, 2009 ; p. 519.

63. Grishkan, I. Ecological stress: Melanization as a response in fungi to radiation. In Extremophiles Handbook; Horikoshi, K., Ed.; Springer: Tokyo, Japan, 2011; pp. 1135-1145. 